\title{
CIENCIA FICCIÓN EN LAS AULAS: EL ETERNAUTA Y LOS POSIBLES RECURSOS PEDAGÓGICOS ${ }^{1}$
}

\author{
SCIENCE FICTION IN THE CLASSROOMS: EL ETERNAUTA \\ AND THE POSSIBLE PEDAGOGICAL RESOURCES
}

Stella Maris Poggian ${ }^{2}$

Existen obras que nacieron para ser visualizadas en imágenes. Cada vez que volvemos a leerlas su visión se amplia y nos conmueve. En el bosque de imágenes que evocamos, sin duda, ilumina un texto escrito hace más de sesenta años; se trata de "El Eternauta” de Héctor Germán Oesterheld.

En la historieta de Oesterheld y Solano López sorprenden la irrupción fantástica en la vida cotidiana, la figura del héroe colectivo, los espacios-escenarios infrecuentes y el sentido de la resistencia como forma de enfrentar lo imprevisible. Su aparición supone uno de los mejores momentos de la historieta argentina.

El comic narra la vida cotidiana de una familia de fines de los años cincuenta que vive tranquilamente en una casa de Buenos Aires. Es de noche y el padre de familia juega a las cartas con tres amigos. Su esposa y su hija Martita descansan en sus cuartos. Nada hace suponer lo que vendrá y el relato tranquiliza y retrotrae a las tertulias de aquellos años.

La historiase inicia con un interesante ejercicio de metaficción. Mientras escribe, un guionista de historietas (que es el propio autor) ve aparecer a Juan Salvo. El personaje se materializa para contar los

1 Originalmente apresentado durante as XIII Jornadas Andinas de Literatura Latinoamericana, na cidade de Rio Branco, Acre, campus da Universidade Federal do Acre, em agosto de 2018.

2 Doctora en Ciencias de la Información en la Universidad Autónoma de Barcelona y docente e investigadora en la Universidad Nacional del Comahue y en el Instituto Universitario Patagónico de las Artes (Argentina). 
acontecimientos que surgirán y que involucran una invasión extraterrestre con voluntad sojuzgadora. Los dibujos que diseñan cada silueta son de Francisco Solano López. La primera parte de El Eternauta se publicó entre 1957 y 1959 y luego tuvo varias continuaciones que no alcanzaron el brillo y la trascendencia de la original.

Aunque hubo intentos por adaptarla al cine, esta obra cumbre de la historieta moderna argentina jamás llegó a las pantallas. Entre las posibilidades que trascendieron estuvo la de que esa realización fuera encarada por Lucrecia Martel. Incluso se conocieron declaraciones de la directora, ventilando ideas provocadoras. También se difundieron debates acerca de la conveniencia de encarar la versión fílmica de la historieta como versión libre o como adaptación fiel.

"En 2008 me convocan para "El Eternauta"; yo había estado preparando un trabajo para el Gobierno de la Ciudad sobre los ríos y estaba tomada por ese mundo. Fue una enorme frustración no poder hacer "El Eternauta", plantea Martel. Cuando una persona se pone a escribir no espera un peso para meterse en el mundo, es imposible. Pensar "El Eternauta" significó salir todas las noches a recorrer los pasajes del libro que yo me imaginaba sean como Villa Luro. Cuando se frustró ese proyecto no sabía cómo salir de ahí, estaba encantada", señaló la realizadora de Zama en un diario de Salta, su ciudad natal. ${ }^{3}$

El tan mentado proyecto se paralizó por problemas con los productores de la película.

Sin embargo, las versiones audiovisuales de ElEternautacobran forma de relatos experimentales en laboratorios académicos que no requieren derechos de autor por ser obras para exclusiva utilización pedagógica.

Algunas de esas experiencias didácticas y de investigación realizadas en materias de Guión y Cine de carreras universitarias de Artes Audiovisuales y Ciencias de la Información patagónicas se llevaron a cabo en 2007. Fueron dos cortos audiovisuales de veinte minutos.

Los estudiantes realizan guiones de adaptación de la primera parte

3 https://www.lagacetasalta.com.ar/nota/88774/espectaculos/lucrecia-martel-fracaso-proyectoeternauta-llevo-zama.html 
del relato que, por lo general, son ejercicios de práctica y presentación de carpetas para realización de proyectos audiovisuales.

La primera parte del escrito refiere a un momento familiar donde irrumpe la magia del viajero espacial que cuenta lo que ocurrió al guionista de historietas. A partir de allí nace el otro relato, el de la invasión extraterrestre.

Pareciera un escrito circular que siempre está comenzando. Para un corto, tanto de versión libre como de adaptación propiamente dicha, estas líneas pueden ser una historia breve de encuentro con un doble, un personaje que surge de la creacióno alucinaciones del artista. La transustanciación en ese sentido resulta creativa y de ejercicio inicial importante para los estudiantes de cine y comunicación en los primeros años.

Hasta el momento los resultados son óptimos en tanto el metalenguaje de un relato dentro de otro supone entrar en el acto de creación iniciático. Un encuentro con el alma del artista.

Luego de años de dictado docente de las materias de Guion de ficción la experienciaacumulada permite sostener que el ejercicio de guionado provoca gratamente a los estudiantes y los estimula.

La realización propone desafíos como los de buscar distintas locaciones, el trabajo con actores, la edición, entre otras aplicaciones del lenguaje cinematográfico, así como el deseo de apuntar a una producción mayor con los riesgos que esto implica. En estos momentos, las nuevas tecnologías digitales facilitan y vuelven más sencillo el desarrollo del texto.

Es interesante recordar queEl Eternauta nació de una pregunta ¿Qué le pasa a una familia si de pronto se ve totalmente aislada del resto del mundo? En la viñeta inicial de la Revista Hora Cero, en septiembre de 1957, se anunciaba: Una cita con el futuro: El Eternauta, memorias de un navegante del porvenir.

Mientras el guionista capta al lector al relatar la vida cotidiana de una familia donde irrumpe lo inesperado, los minuciosos dibujos de Solano López atrapan por sus pinceladas de Buenos Aires que nos remiten a lugares conocidos o por conocer. La versión primera fue en blanco y negro, mientras que la segunda apareció en color.

Para Oesterheld la historieta remite a Robinson Crusoe y a su propia 
fascinación por la historia del hombre y su destino. Aunque en su versión el sujeto se transfigura, es el hombre con familia y amigos el que prevalece frente al desasosiego: "Por eso la partida de truco, por eso la pequeña familia que duerme en el chalet de Vicente López, ajena a la invasión que se viene. Ese fue el planteo, lo demás creció sólo..." (VV.AA., 2007, p. 13).

En palabras de Oesterheld, es necesario defender la historieta. Condenarla en conjunto estan irracional como negar el cine en conjunto porque hay películas malas.El autor entendía a la historieta "como fuerte, recia y alegre, violenta y humana, la que sorprende al lector porque es nueva, porque es original, moderna, de hoy, de mañana si hace al caso" (VV.AA., 2007, p. 6).

\section{La investigación del relato}

En 2007 sucedieron otras situaciones ligadas a El Eternauta y la investigación académica. En esos días una estudiante planteó el desafíode acompañarla en una investigación sobre el tema. Después de recorrer y pensar en la metodología se abocó en un trabajo de tipo exploratorio. Intentó conocer y reconocer la imagen del comic desde perspectivas visuales y audiovisuales. A medida que se familiarizaba con la temática le costaba encontrar textos sobre el autor y su historia.No obstante, al presentar su tesisdos años después, había recopilado tantos escritos que pudo llenar una mesa con libros sobre la temática estudiada.

Entre esos textos se destacaba un libro producido para la "Muestra 50/30: 50 años con el Eternauta.... 30 años sin Oesterbeld”, realizada en el marco de un homenaje al autor, desaparecido junto a sus cuatro hijas en 1977.

En la invitación a la muestra y presentación del libro leemos: este es uno de esos casos emblemáticos en que autor y obra están ligados en más de una manera. $Y$ es precisamente por ese motivo que no resulta extraña la doble conmemoración que se propone: 50 años de la primera publicación de El Eternauta, 30 años de la desaparición de Héctor Germán Oesterheld.Con 50/30 no solo se invita a descubrir o a releer El Eternauta, sino también a un recorrido por la vida y obra del escritor al quese brinda homenaje. 
"La historieta - al decir del propio Oesterheld - si se la hace bien, puede ser más que simple entretenimiento, puede ser la herramienta educativa del futuro", señalaron los organizadoresen la presentación del libro.

La exposición contó con materiales de la colección, originales y los surgidos de una convocatoria adibujantes. Se buscaba difundir la obra de Oesterheld a través de jóvenes artistas. Una segunda convocatoria reunía a profesionales que exponían personajes oesterheldianos.

En el libro homenaje aparecen dibujantes de distintas generaciones recreando portadas imaginarias de la revista Hora Cero Semanal. Entre estos artistas hay varios que trabajaron junto a Oesterheld, otros, los más jóvenes, citaban al autormediante la interpretación posterior.

Aquellas horas fueron acompañadas por una muy emotiva conferencia de su viuda, Elsa Sánchez de Oesterheld. Recordemos que el escritor y sus hijas permanecen desaparecidos. La obra y la historia de su autor reflejan un juego de espejos y de anticipación mediante la idea de una invasión extraterrestre que parte de lo cercano para expandirse al terreno de lo universal. Dice Rodríguez Van Rosselt, en el libro de la muestra:

El Eternauta representa una larga saga de episodios inscriptos en la épica grupal enfrentando una espantosa invasión que llega del espacio exterior. El grupo se va ampliando hasta formar una inmensa marea donde civiles y militares, una sociedad sin Estado, trata de contener a los extraños a pesar de todos los fracasos. Esto es esencial en la trama de la historia: enfrentar los conflictos, en este caso con las fuerzas de la naturaleza, sin decaer (VV.AA., 2007, p. 28).

Anclados en estudios vinculados con la ficción, los proyectos de investigación que integramos abordan la temática de lo narrativo, poniendo especial énfasis en aquellos relatos que trabajan desde la representación de lo fantástico.

Tenemos en cuenta la narración audiovisual como componente a explorar en relación con la literatura, los géneros y su intertextualidad. Intentamos analizar la funcionalidad de las tramas, argumentos o componentes. Nos interesa observar al cine como expresión plástica en tanto transmite mensajes a través de las interacciones cromáticas de 


\section{ENSAIO}

colores cálidos o fríos, así como en las interpretaciones de sus posibles narrativos en el amplio espectro del lenguaje cinematográfico.

"El Eternauta"es un escrito de constante consulta tanto en el mundo académico-artístico, como en el terreno de la divulgación. Su estudio requiere revisión por suconfiguración del pasado, la revisión de la memoria, así como también por lo que proyecta a futuro. En un mundo cada vez más complejo, la ciencia ficción, la metaficción y el misterio de la creación nos impulsan a observar atentamente escritos con vocación de epifanía, sobre todo por su impacto revelador en jóvenes que están en pleno proceso de formación.

\section{El futuro del Eternauta}

Nos gusta pensar en la realización de una película sobre este comic por entregas, que luego fue libro, que después resultó una emblemática exposición y hoy sigue siendo leído como texto de anticipación.

Si bien el cine argentino no ha tenido un amplio recorrido en el terreno de la ciencia ficción, se pueden citar películas como Una luz en la ventana (1942), de Manuel Romero; Extraña invasión (1965), coproducción argentina estadounidense de Emilio Vieyra; La guerra del cerdo (1969), de Leopoldo Torre Nilsson; Invasión (1969), de Hugo Santiago; Más allá de la Aventura (1980), de Oscar Barney Finn; Hombre Mirando al sudeste (1987), de Eliseo Subiela; Lo que vendrá (1988), de Gustavo Mosquera; No te mueras sin decirme a dónde vas (1995), de Eliseo Subiela y, más cercanas en el tiempo, Moebius (1996), de Mosquera; La sonámbula. Recuerdos del futuro (1998), de Fernando Spinner; La antena (2007), de Estaban Sapir; Los últimos (2017), de Nicolás Puenzo; Pájaros volando (2010), de Néstor Montalbano, así como los filmes de animación Cóndor Crux (2000), de Juan Pablo Buscarini, Swan Glecer y Pablo Holcer y Mercano, el Marciano (2002), de Juan Antín, entre otras realizaciones.

Nos centraremos brevemente en dos películas de las más citadas que, además, podemos relacionar con El Eternauta, observando similitudes. El film más recordado sobre el género es Invasión, rodado por Hugo Santiago afinales de los años sesenta. Jorge Luis Borges y Adolfo Bioy Casares escribieron el argumento. La cinta mostraba la invasión a la ciudad de 
"Aquilea" y la resistencia ejercida por un grupo liderado por Don Porfirio ante la indiferencia del resto de los habitantes. La película fue maltratada durante la dictadura al punto que en 1978 alguien robó ocho bobinas del negativo original del film, que estaban en laboratorio. "Fue un operativo", diría luego el propio Santiago.

Otra importante obra ligada a la ciencia ficción es Hombre mirando al sudeste, de Eliseo Subiela. Trata la historia de un enfermo mental que vive en un hospital psiquiátrico y en la terapia dice que es un extraterrestre. La transferencia que experimenta el médico lo lleva a dudaracerca de la fabulación del paciente.

Ambas películas presentan personajes que vienen de otros espacios para contarnos una historia. En Invasión la resistencia de sus personajes se emparenta con la obra de Oesterheld. En Hombre mirando al Sudeste, la presencia del supuesto extraterrestre sirve para cambiar el orden establecido en el hospital, resaltar lo inesperado y la extrañeza.

En un terreno aún inexplorado como es el audiovisual de ciencia ficción en Argentina, la representación audiovisual de El Eternanta permitiría ampliar el espectro de nuestro cine y visualizar un texto luminoso, gestado casi a manera de distopia y novela de anticipación.

Un desafío de la obra es trabajar el héroe colectivo, eje central el texto.

La lectura o relectura siempre permiten nuevas interpretaciones. Relato atemporal vinculado con la mitología griega, con las tesis acerca del camino del héroe y la visión del antihéroe, el texto nos interpela en su posible adaptación.

El futuro no lo conoce nadie, pero imaginarlo no cuesta nada. Incentivar a los jóvenes realizadores a aventurarse en una obra que puede cobrar una nueva vida, no es poca tarea. En eso estamos cada día.

\section{Referencia}

VV.AA. 50 años con El Eternauta, 30 años sin Oesterheld. Buenos Aires: Ministerio de Educación de la Nación, 2007.

Data de recebimento: 02/12/2018

Data de aceite: $28 / 12 / 2018$ 